\title{
Multi-Informant Assessment of Bullying in Austrian Schools
}

\author{
Antonia Paljakka $^{1 *}$, Susanne Schwab ${ }^{1,2}$ and Carmen L. A. Zurbriggen ${ }^{3}$ \\ ${ }^{1}$ Centre for Teacher Education, University of Vienna, Vienna, Austria, ${ }^{2}$ Optentia Research Focus Area, North-West University, \\ Vanderbililpark, South Africa, ${ }^{3}$ Faculty of Humanities, Education and Social Sciences, University of Luxembourg, Esch-sur-Alzette, \\ Luxembourg
}

This study explores the agreement of bullying reports from different perspectives. Nominations and (self and peer) ratings of 721 students $(50.5 \%$ boys, $49.5 \%$ girls, aged 9-11), 46 teachers (91.3\% female, 8.7\% male; $M_{\text {age }}=40.28$ years, $S D_{\text {age }}=1.6$, teaching experience between 2 and 36 years, $M_{\text {experience }}=15.16, S D_{\text {experience }}=1.68$ ), 439 mothers, and 363 fathers were analyzed. Measures included a modified version of the Revised Olweus Bully/Nictim questionnaire (OBVQ) as well as nomination items, with variables on physical and relational bullying and victimization, and frequency of experience. For descriptive analyses, group comparisons and correlations were performed and to test

OPEN ACCESS

Edited by:

Bernhard Ertl,

Munich University of the Federal Armed Forces, Germany

Reviewed by:

Candido J. Ingles, Miguel Hernández University of Elche,

Spain

Wanderlei Abadio de Oliveira, Pontifical Catholic University of Campinas, Brazil

*Correspondence:

Antonia Paljakka

antonia.paljakka@univie.ac.at

Specialty section:

This article was submitted to Educational Psychology,

a section of the journal

Frontiers in Education

Received: 20 May 2021 Accepted: 13 September 2021 Published: 30 September 2021

Citation:

Paljakka A, Schwab S and Zurbriggen CLA (2021) Multi-Informant Assessment of Bullying in Austrian Schools.

Front. Educ. 6:712318. doi: 10.3389/feduc.2021.712318 the dimensional structure of the modified Revised OBVQ we fitted a categorical confirmatory factor analysis (CCFA) for all four raters. To estimate the degree of agreement between the four raters, we applied a simple multitrait-multimethod (MTMM) analysis in a CCFA framework. Results indicated that teachers are more likely to recognize physical bullying than relational bullying. Significant gender effects were found, with more frequent nominations for boys and a larger gender effect for physical bullying. Overall, teachers reported the highest levels of bullying, and students reported significantly higher levels of victimization compared to the other raters. In terms of bullying, the MTMM model revealed a slightly higher agreement between students and parents than between students and teachers. The findings further indicate a tendency for lower agreement between student and adult reports than among adults' reports. The notably high agreement between the ratings of mothers and fathers for both bullying and victimization supports the research strategy to include only one parent. Although bullying is assessed from various perspectives, the study does not provide prevalence estimates of bullying in Austria.

Keywords: school bullying, multi-informant assessment, self-report, peer-nominations, teacher-reports, teachernominations, parent-reports

\section{INTRODUCTION}

The origins of systematic research on school bullying date back to Dan Olweus' first publications on the topic of "Mobbing" (Olweus, 1973; 1978). After more than 40 years of research, the scientific community largely agrees that bullying can be differentiated from normal or (other) aggressive behavior through the following features: intention of the perpetrator(s), repetition of violating activities, and an imbalance of power between the perpetrator(s) and victim(s) (Olweus, 1993; 1996a). Although there is broad agreement on the definition of bullying, the final word has not yet 
been said in the debate on the best method for assessing bullying and the most reliable group of informants - this has also been referred to as the "Achilles heel" of research on bullying (Cornell et al., 2006).

The methods to assess this complex and often hidden behavior range from direct observation to self-reports, peer, teacher, or parent reports, ratings, sociometric nominations, or diary measures, and combinations thereof. An additional difficulty in assessing bullying is that the level of agreement varies not only between informants and methods, but also in terms of bullying and victimization, i.e., bullying others or being bullied. Since bullying involves various participants and is influenced by multiple factors, Hymel and Swearer (2015, p. 294) state, 'there may be no single "gold standard" for accuracy.'

This study investigates the agreement of bullying reports from students, teachers and parents using ratings and sociometric nominations. In the following, we will outline the most common methods of assessing bullying and also the levels of agreement between different groups of informants. We will further point out the lack of country-specific research on bullying in Austria and try to extend this by examining multiinformant data and its agreement.

\section{Self-Report of Bullying}

Students' self-reports are for several reasons the most common source of information on bullying in the classroom. The Olweus Bully/Victim questionnaire (OBVQ; Olweus, 1996b) is a prominent example of a self-report measure and is probably the most commonly used tool (Lee and Cornell, 2009). Selfreports are a rapid, economical, and efficient method of collecting data from a large number of students and are directed at those who know firsthand of the students' involvement in bullying or whether they are victimized (Pellegrini, 2001; Cornell et al., 2006; Branson and Cornell, 2009). From a prevalence estimation perspective, Solberg and Olweus (2003) strongly favored selfreports over peer nominations. Nevertheless, despite the benefits of self-reports, concerns have been raised about bias in relation to social desirability, intentional exaggeration, or the fear of social sanctions; for this reason, validity screening procedures are advised (Pellegrini, 2001; Branson and Cornell, 2009; Cornell and Bandyopadhyay, 2010). Further, Cornell and Brockenbrough (2004) argue that little is known about the accuracy of self-reports due to the anonymity involved.

\section{Peer Nomination of Bullies and Victims}

Considering the social nature of bullying, including that it takes place within a school class, which is a relatively stable social group (Salmivalli et al., 1996; Atria et al., 2007), relying solely on selfreports could be too short-sighted to investigate whether, how, and to what extent bullying occurs in the classroom. Peer nominations may provide access to information that is - in the case of bullying - typically hidden from adults (Pellegrini, 2001). The procedures may vary, e.g., only same-gender peers are asked, peers nominate a fixed number of students, nominating all students that come to mind or rating or ticking from a list of all classmates (Pellegrini, 2001). However, in terms of peer ratings, students judging their peers based on reputation, even after their bullying behavior may have already changed, cannot be avoided (Branson and Cornell, 2009). Further, no obvious cutoff exists for identifying bullies or victims (Solberg and Olweus, 2003). Even though only small to moderate correlations $(r=0.10-0.42)$ were found between self- and peer reports, with lower correlations for bullying others than for victimization (Pellegrini, 2001; Cornell and Brockenbrough, 2004; Cole et al., 2006; Branson and Cornell, 2009; Lee and Cornell, 2009), Juvonen et al. (2001) argue in favor of combining these two sources of data to obtain multiple perspectives for a better understanding.

\section{Teacher and Parent Report of Bullying}

Teachers are often the closest adults when bullying occurs and therefore the first possible points of contact for the students involved (Yoon and Bauman, 2014; Bilz et al., 2017; Wachs et al., 2019). Still, their perception of bullying depends to a large extent on its type. Teachers are better able to recognize physical rather than relational bullying (e.g., Chen et al., 2018), which might be because the latter's appearance and consequences are harder to identify or because teachers perceive physical bullying as more serious than other types (Boulton, 1997; Bauman and Del Rio, 2006; Bell and Willis, 2016). With regard to the school setting as an environment for bullying, the first research question of the current study asks how peer and teacher nominations correspond.

Within the family context, parents are the most likely group of people to find out or be told about bullying at school, either if the child was directly involved or if they witnessed it. Moreover, students are more likely to inform parents than teachers about bullying and victimization (Fekkes et al., 2005; Smith, 2014; Blomqvist et al., 2019). However, generally (if students and their parents and teachers are not matched), students tend to report higher bullying rates than parents or teachers (Stockdale et al., 2002; Holt et al., 2008). Hymel and Swearer (2015) consider teacher and parent reports to be "more suspect" because bullying happens primarily in the peer group and in particular, in places out of the sight and control of adults (Vaillancourt et al., 2010). Therefore, the second research question of this study aims to examine the agreement between students', parents' and teachers' reports of bullying.

\section{Multiple Informants on Bullying}

A few studies so far combined two or three of the aforementioned data sources to explore bullying (Pellegrini and Bartini, 2000; Stockdale et al., 2002; Cornell and Brockenbrough, 2004; Holt et al., 2008; Christensen et al., 2012; Demaray et al., 2013). For example, Demaray et al. (2013) examined the agreement among the perceptions of students, teachers, and parents regarding victimization using the Revised OBVQ (Olweus, 1996a). The overall results revealed students reporting significantly higher victimization levels than their parents and teachers. Moreover, parents reported significantly more victimization than their child's teacher. The correlation levels of victimization had moderate agreement between students and parents as well as between parents and teachers and low agreement between teachers and students. Newgent et al., 2009 found parents reporting higher levels of peer victimization than students and teachers. 
Ladd and Kochenderfer-Ladd (2002) compared single-versus multi-informant victimization measures using short rating scale questionnaires in combination with nominations (for peers). The results indicated correlations ranging between 0.20 and 0.40 of the data from the four groups of informants (self, peer, teacher, and parent). Considering informants from the social environment in which bullying is embedded can help enrich the understanding of bullying and inform prevention and intervention development. Against this backdrop, the present study aims to explore multi-informant data about bullying in Austrian schools.

\section{Bullying in Austrian Schools}

The majority of studies examining bullying in Austria focus on a few specific topics. These are for example the Viennese Social Competence Training (ViSC), a program against violence designed especially for secondary schools (5th-8th grade) in Austria (Spiel and Strohmeier, 2011; Gradinger et al., 2016; Yanagida et al., 2019; Strohmeier et al., 2021), migration and bullying (Strohmeier and Spiel, 2003; Strohmeier and Wagner, 2019; Strohmeier and Gradinger, 2021), or more recently cyberbullying (Gradinger et al., 2012; Graf et al., 2019a, 2019b) and teachers' role in (cyber)bullying (Burger et al., 2015; Gradinger et al., 2017; Strohmeier and Gradinger, 2021). Atria et al. (2007) assessed the variability of the occurrence of bullying and victimization in Austria on a school-class level using self-reports and (partly) peer nominations. They found a variability of bullying and victimization ranging from 0 to $54.5 \%$.

Observing the prevalence rates of bullying in Austrian schools, we have to rely mainly on the data of large-scale cross-national surveys such as the Health Behavior in School-aged Children (HBSC) surveys of the World Health Organization, which are based on students' self-reports. According to the HBSC surveys, Austria was for many years one of the countries with the highest bullying prevalence rates (Craig and Harel, 2004; Currie et al., 2008; Molcho et al., 2009; Molcho, 2012; Walsh and Cosma, 2016). The last HBSC survey in the year $2017 / 18$ reveals that in Austria, $8 \%$ of adolescents are victims of bullying (Inchley et al., 2020). Compared to the other countries surveyed, Austria recorded the biggest decline in bullying others for both genders since 2014 . To the time of survey $7 \%$ of boys and $3 \%$ of girls became involved in repeatedly bullying others over the previous couple of months. The authors of the Austrian survey suggest this decline to be the result of including "social learning" and other social cohesion activities into school curricula. They also discuss that the prevalence of bullying in Austria was relatively high and that schools were happy to accept help to counteract bullying (Felder-Puig et al., 2019). Unlike the HBSC study, however, the OECD Programme for International Student Assessment (PISA) records an increase in the prevalence of bullying in Austria. In the latest PISA survey (OECD, 2019), about $23 \%$ of Austrian students reported being bullied at least a few times a month, which is in line with the average for OECD countries but about $4 \%$ higher than in the 2015 survey (OECD, 2017). The variability of prevalences between the HBSC and PISA survey may be due to different methodological approaches and assessment issues (Casper, 2021). Studies that empirically investigate the reasons for the changes in bullying prevalence in Austria are lacking so far.

The present study does not allow to deduce bullying prevalence estimates, but by including sources other than selfreport, a more comprehensive picture of bullying in Austrian schools can be obtained.

\section{Aim of the Current Study}

The primary objective of this study is to explore the agreement of bullying reports from different perspectives. Based on the current state of research, the following hypotheses specify the above mentioned research questions. In connection with the first question, whether and to what extent the results from peer and teacher nominations regarding physical and relational bullying correspond, we expect gender effects for the involvement in bullying, with more frequent ratings for boys (Smith et al., 2019). We also assume that there are higher levels of physical bullying than relational bullying for boys and a reverse relation for girls (Björkqvist et al., 1992; Carbone-Lopez et al., 2010). As discussed above, teachers are more likely to recognize physical rather than relational bullying, which is why we further expect stronger correlations between teachers and peer rating for physical bullying compared to relational bullying.

Second, we expect to find higher agreement between students' and parents' reports than between students' and teachers' reports. Due to contradictory findings, no clear predictions can be made for the levels of bullying and victimization reported from the different raters. Nevertheless, we assume that teachers are more likely to recognize bullying than victimization and for parents, we expect it to be the converse because students seem to prefer reporting victimization to their parents rather than to teachers (Houndoumadi and Pateraki, 2001). Due to limited past research taking the perspective of both parents - mothers and fathers into account, the analysis in this area is rather exploratory.

\section{MATERIALS AND METHODS}

The data of the present study originated from the "Attitudes Towards Inclusive Schooling - Students, Teachers and Parents" (ATIS-STEP) survey (Schwab, 2018). In total, data was collected from 48 inclusive classes in the 4 th grade (primary education, age range: 9-11 years) from 37 schools in Styria (a federal state in Austria). The local school authorities of Styria accorded ethical approval for this study. The schools were selected from city and rural areas using purposive sampling. The aim was to include only schools which had 4 th grade classes with at least one student with formally diagnosed special educational needs (SEN). A number of 40 classes was aspired and once 48 classes agreed to participate, no more schools were contacted. Data collection took place at the beginning of the school year in autumn 2016. Of those schools that agreed to take part in the study, the teachers of the 4 th grade classes were asked to fill out the teachers questionnaire. The student questionnaires were 
administered by trained project members in a paper and pencil format. The participating students were asked to pass the mothers' and fathers' version of the questionnaire to their parents. Parent questionnaires were returned to teachers in a sealed envelope. Prior to the study, informed consent was obtained from the parents/legal guardians of the participants.

\section{Samples}

Students: The sample of this study comprised 721 students (50.5\% boys, $49.5 \%$ girls) aged $9-11.92$ students (12.8\%) were diagnosed with SEN, primarily due to learning disabilities (approx. 79\%) and behavioral disabilities (approx. 10\%). 163 students $(22.9 \%)$ spoke a language other than German at home. The majority of students live with both parents, 133 students $(18.5 \%)$ live with their mother, 14 (1.9\%) live with their father and 12 students (1.7\%) do not live with their parents.

Parents: The sample included 482 mothers and 400 fathers of the participating students. The language spoken in the family indicates that around $25 \%$ of the parents had a migrant background. With regard to the highest education level, 95 mothers and 87 fathers had graduated from university, 97 mothers and 73 fathers finished academic secondary school, 169 mothers and 151 fathers completed the apprenticeship certification exam, and 84 mothers and 51 fathers finished middle school (the remaining parents had another completed education or gave no information). For 384 (53.3\%) of the 721 students, both parents participated in the study, although in total, not every questionnaire was filled out completely (Schwab, 2018, p. 50). More specifically, we could use the ratings from 439 mothers and 363 fathers for our analyses.

Teachers: A total of 87 teachers participated in the ATIS-STEP study, whereas in the present study, data of only 46 regular class teachers $\left(91.3 \%\right.$ female, $8.7 \%$ male; $M_{\text {age }}=40.28$ years, $S D_{\text {age }}=$ 1.6 years) was included. The teaching experience varied between 2 and 36 years $(M=15.16$ years, $S D=1.68$ years $)$. However, from 43 teachers, individual ratings about their students $(n=657$ students) were obtained.

\section{Measures}

The student and teacher questionnaires encompassed (Germantranslated) sociometric nomination items based on the measures used by Sturaro et al. (2011) and De Laet et al. (2015). From the five sociometric nomination items in total, two items were specifically connected to bullying - one associated with physical aggression ("Who hits, kicks, or pushes other children at school?") and one to relational aggression ("Who tries to make classmates not being liked by others by spreading rumors about them or talking behind their backs?"). The students and teachers were invited to write down the names of as many of their classmates and students, respectively, as they liked who fit the description but not nominate themselves.

To assess bullying and victimization, students, teachers, and parents completed also a modified (German-translated) version of the Revised OBVQ (Olweus, 1996b). In contrast to the original version with 36 items, a total of 10 items were included, and the German term "Mobbing" was used instead of bullying. Two items (global items) asked, on a general level, how often in the last couple of months the student had participated in bullying someone else or had been bullied. Each of the two global items on bullying and victimization was followed by four more specific items on the type of bullying (e.g., "I have insulted someone else") and victimization (e. g. "I was excluded by others, e.g., at play/sports or joint activities"). The participants were asked to rate the frequency of their experiences over the last few months with Likert-type items in four response categories ("not at all," "once or twice," "two or three times a month," “once a week"). The student version of the questions was adapted for the teacher and parent versions of the questionnaire by changing the applicable wording to "the child" (teachers) and "my child" (parents). A sample bullying item from the teacher questionnaire is "the child was insulted by others" and a sample victimization item from the parents' questionnaire is "my child was physically assaulted (beaten, kicked, and pinched)."

Only the two global items referred directly to the term "Mobbing." Since all the other items as well as the sociometric nominations used behavioral descriptions of bullying without using the term, bullying was not explained separately to the participants. Corresponding to the use of the modified version of the Revised OBVQ, the operational definition of bullying guiding the study is based on Olweus' (1993; 1996a) definition mentioned earlier in the introduction.

\section{Analysis}

First descriptive analyses, the group comparisons and correlations were performed using SPSS Version 26. In order to calculate the sociometric nominations, we first counted how often each student was nominated by their peers as well as teachers regarding the bullying items. For descriptive analyses, data was entered in SPSS Version 26. Analyses on the agreement between students, parents, and teacher reports were performed using Mplus Version 8.2 (Muthén and Muthén, 1998-2017). In accordance with the recommendations of Nussbeck et al. (2006), we applied the robust weighted least squares mean- and varianceadjusted (WLSMV) estimator. The WLSMV estimator is specifically designed for ordinal data. To test the dimensional structure of the modified Revised OBVQ, we fitted a categorical confirmatory factor analysis (CCFA) for all four raters (student, teacher, mother, father) separately, thus only the available data per type of rater were included. For student and teacher ratings, we used the complex sample option to adjust the standard errors according to the clustered data structure. The internal consistency of the scales was evaluated by means of McDonald's omega $(\omega)$. The model fit was assessed with the chi-square test and the following goodness-of-fit indices: the comparative fit index (CFI), the Tucker-Lewis index (TLI), the root mean square error of approximation (RMSEA), and the standardized root mean square residual (SRMR). TLI and CFI values greater than 0.95 reflect a good fit between the model and the data. For the SRMR, values close to or less than 0.08 are recommended ( $\mathrm{Hu}$ and Bentler, 1999; Marsh et al., 2004). For the RMSEA, several authors differentiate between values less than 0.05 as indicating a good fit, and values between 0.05 and 0.08 as indicating an acceptable 


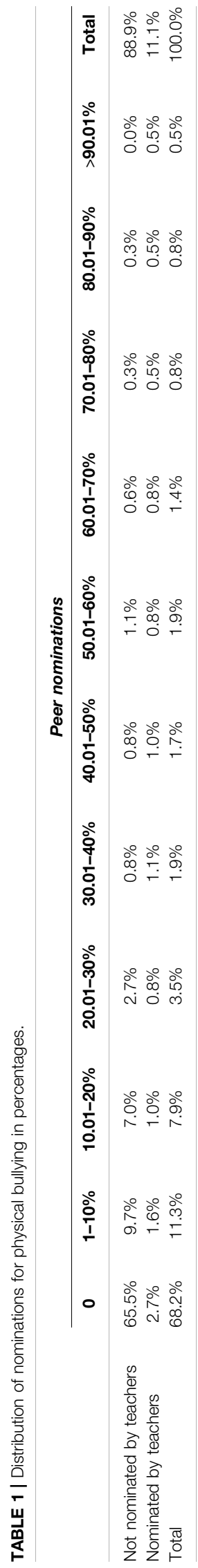

fit (e.g., Browne and Cudeck, 1993; Wang and Wang, 2012). To estimate the degree of agreement between the four raters, we applied a simple multitrait-multimethod (MTMM) analysis in a CCFA framework (e.g., Eid et al., 2008). In this CCFA-MTMM, there were separate latent factors for the two traits-bullying and victimization-for each type of rater.

\section{RESULTS}

\section{Results From the Sociometric Nominations}

Descriptive results showed that out of the 43 classes, in 14 classes (32.6\%), not a single student was nominated for physically bullying others. Similarly, for relational bullying, 14 teachers did not nominate a single student in the class. In total, around $11.1 \%$ of all students ( $20.2 \%$ boys and $2.2 \%$ girls) were nominated by the teacher for physical bullying and $8.7 \%$ for relational bullying ( $6.4 \%$ boys and $11 \%$ girls). According to the students' nominations, in one class (2.3\%), not a single student nominated any peer for physical or relational bullying; further, in three more classes, not a single student was nominated for physical bullying (9.3\%). More details on descriptive results are depicted in Tables 1, 2. The tables show the distributions of the teacher and peer nominations for physical bullying (Table 1) and for relational bullying (Table 2) in percentages. We used the percentages of peer nominations as reference and compared them with teacher nominations, because nomination was done by only one teacher while all the peers nominated their classmates. Therefore, multiple peer nominations existed, which were then related to the number of peers in class.

However, students' data indicated a large fluctuation in how often a student is rated as a bully. For physical bullying, the mean score was $1.23(S D=2.76)$ while the range was between 0 and 19 nominations per student. For relational bullying, the mean score was lower $(M=0.60, S D=1.14)$ and the range was between 0 and 10 nominations per student. Comparing the results relating to boys (physical bullying: $M=2.20, S D=3.44$; relational bullying: $M=0.75, S D=1.31$ ) and girls (physical bullying: $M=0.29, S D$ $=1.29$; relational bullying: $M=0.46, S D=0.92$ ) using a multivariate analysis of variance showed a significant, mediumsized gender effect $(F 2,626=46.85, p<0.01, \eta 2=0.13)$. Females were rated to physically bully significantly less often than boys $(F 1,627=85.49, p<0.01, \eta 2=0.12)$ and to relationally bully others significantly less often than boys $(F 1,627=9.83, p<0.01)$, the latter however, only small in effect size $(\eta 2=0.02)$.

Point-biserial correlations indicated that the two teacher variables on physical ("Who hits, kicks, or pushes other children at school?") and relational bullying ("Who tries to make classmates not being liked by others by spreading rumors about them or talking behind their backs?") correlated with $r_{\mathrm{PB}}=0.20(p<0.01)$ and the (same) two variables of the peers ("Who hits, kicks, or pushes other children at school?" and "Who tries to make classmates disliked by others by spreading rumors about them or talking behind their backs?") by $0.43(p<0.01)$. Table 3 shows the correlations between the teacher and peer nominations regarding physical and relational bullying. The results indicated that the correlations between teacher and 
TABLE 2 | Distribution of nominations for relational bullying in percentages.

\begin{tabular}{|c|c|c|c|c|c|c|c|}
\hline & \multicolumn{7}{|c|}{ Peer nominations } \\
\hline & 0 & $1-10 \%$ & $10.01-20 \%$ & $20.01-30 \%$ & $30.01-40 \%$ & $40.01-50 \%$ & Total \\
\hline Not nominated by teachers & $63.9 \%$ & $17.8 \%$ & $6.0 \%$ & $2.4 \%$ & $1.0 \%$ & $0.2 \%$ & $91.3 \%$ \\
\hline Nominated by teachers & $2.7 \%$ & $2.4 \%$ & $2.2 \%$ & $1.0 \%$ & $0.5 \%$ & $0.0 \%$ & $8.7 \%$ \\
\hline Total & $66.6 \%$ & $20.2 \%$ & $8.3 \%$ & $3.3 \%$ & $1.4 \%$ & $0.2 \%$ & $100.0 \%$ \\
\hline
\end{tabular}

TABLE 3 | Correlations between teacher and peer nominations.

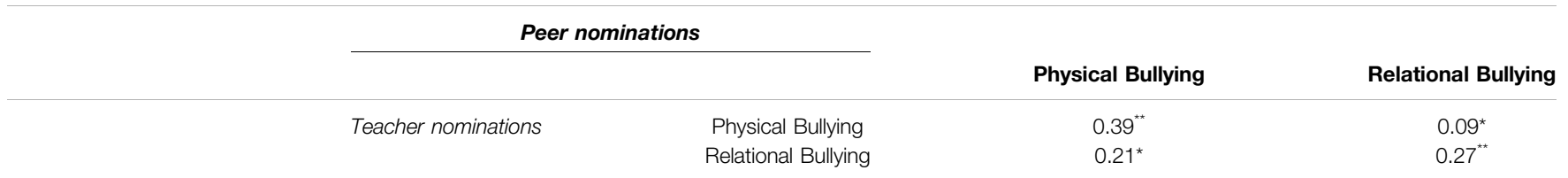

Note. ${ }^{* *} p<0.01,{ }^{*} p<0.05$.

TABLE 4 | Distribution parameters for bullying and victimization ratings.

\begin{tabular}{|c|c|c|c|c|c|c|c|c|c|}
\hline & & \multicolumn{4}{|c|}{ Bullying } & \multicolumn{4}{|c|}{ Victimization } \\
\hline & & $M$ & $S D$ & Skewness & Kurtosis & $M$ & $S D$ & Skewness & Kurtosis \\
\hline \multirow[t]{2}{*}{ Self-ratings } & boys & 1.45 & 0.58 & 1.77 & 3.42 & 1.61 & 0.70 & 1.22 & 0.82 \\
\hline & girls & 1.24 & 0.39 & 2.13 & 4.90 & 1.49 & 0.61 & 1.53 & 2.01 \\
\hline \multirow[t]{2}{*}{ Mother ratings } & boys & 1.25 & 0.37 & 2.07 & 5.04 & 1.41 & 0.60 & 2.11 & 4.92 \\
\hline & girls & 1.14 & 0.29 & 3.31 & 16.64 & 1.29 & 0.48 & 2.60 & 9.36 \\
\hline \multirow[t]{2}{*}{ Father ratings } & boys & 1.24 & 0.36 & 1.83 & 3.43 & 1.32 & 0.49 & 2.61 & 9.43 \\
\hline & girls & 1.13 & 0.26 & 3.72 & 21.77 & 1.27 & 0.44 & 2.07 & 4.70 \\
\hline \multirow[t]{2}{*}{ Teacher ratings } & boys & 1.59 & 0.69 & 1.36 & 1.44 & 1.40 & 0.47 & 1.84 & 5.37 \\
\hline & girls & 1.31 & 0.51 & 2.28 & 6.72 & 1.21 & 0.36 & 1.99 & 4.01 \\
\hline
\end{tabular}

peer nominations within the same variable were higher than for mixed variables.

\section{Results From the Student, Parent, and Teacher Ratings}

Table 4 shows the mean and standard deviations for the bullying and victimization ratings for all raters. According to the skewness and kurtosis, some of the data was not normally distributed. The results of a univariate analysis for repeated measures (the rater was used as the repeated factor) indicated a significant, large main effect for the rater $(F 3,260$ $=20.43, p<0.01, \eta 2=0.19)$ but no significant interaction effect between rater and gender $(F 3,260=1.23$, n. s., $\eta 2=0.01)$. The teacher rated bullying the highest $(M=1.37, S D=0.58)$ followed by students $(M=1.33, S D=0.48)$, fathers $(M=1.17, S D=0.32)$, and mothers $(M=1.16, S D=0.31)$.

Similarly, for victimization, a significant large effect for the rater was found $(F 3,260=15.40, p<0.01, \eta 2=0.15)$, while the interaction between the rater and gender was not observed to be significant $(F 3,260=1.00$, n. s., $\eta 2=0.01)$. Students rated being a victim significantly higher $(M=1.52, S D=0.64)$ compared to mothers $(M=1.29, S D=0.52)$, fathers $(M=1.29, S D=0.47)$, and teachers $(M=1.24, S D=0.38)$. However, the other three raters (mothers, fathers, and teachers) did not differ significantly.

\section{Agreement Between Student, Teacher, and Parent Ratings}

Before analyzing the four versions together in one MTMM model, CCFA models were estimated separately for the student, teacher, mother, and father reports. Table 5 reports the fit statistics (Model 1-4). In general, all the four models showed an appropriate fit to the data. Two exceptions were the significant chi-square test for all the four models and the relatively high RMSEA value for the teacher version. However, the chi-square test is widely criticized for being too sensitive to sample size. Overall, the two-factor structure of the modified Revised OBVQ was supported for all the four versions.

The CCFA-MTMM model fitted the data well, $\chi_{\text {WLSMV }}^{2}(187$, $N=721)=952.60, p<0.001 ; \mathrm{CFI}=0.970, \mathrm{TLI}=0.967$, RMSEA $=0.021[0.017,0.025]$, SRMR $=0.083$ (Table 5, Model 5). Table 6 presents the correlations of the CCFA-MTMM matrix and the internal consistencies of the scales (values in parentheses). The internal consistencies of the scales were all high. The $\omega$ coefficients were slightly lower for student reports $(0.84,0.80)$ than for teacher and parent reports $(0.86 \leq \omega \leq 0.94)$.

The intercorrelations between the two scales for each method (i.e., heterotrait-monomethod correlations) were all significant and relatively high, with the lowest correlation for student reports (0.72) and the highest for teacher reports (0.88). The factor correlations between the different raters (i.e., monotrait- 
TABLE 5 | Summary of model fit indices.

\begin{tabular}{|c|c|c|c|c|c|c|c|}
\hline Model & $\chi_{\text {wismv }}^{2}$ & $d f$ & $p$ & CFI & TLI & RMSEA [90\% Cl] & SRMR \\
\hline Student $^{\mathrm{a}}$ & 138.67 & 34 & $<0.001$ & 0.970 & 0.961 & $0.066[0.054,0.077]$ & 0.052 \\
\hline Mother & 113.13 & 34 & $<0.001$ & 0.978 & 0.971 & $0.061[0.056,0.084]$ & 0.073 \\
\hline Father & 114.59 & 34 & $<0.001$ & 0.977 & 0.970 & $0.079[0.056,0.084]$ & 0.066 \\
\hline CCFA-MTMM & 952.60 & 712 & $<0.001$ & 0.970 & 0.967 & $0.021[0.017,0.025]$ & 0.083 \\
\hline
\end{tabular}

Note. CCFA = categorical confirmatory factor analysis; $M T M M=$ multitrait-multimethod analysis; CFI = comparative fit index; TLI = Tucker-Lewis index; RMSEA = root mean square error of approximation; $90 \% \mathrm{Cl}=90 \%$ confidence interval; SRMR = standardized root mean square residual. ${ }^{a}$ CFA models for student and for teacher were calculated using the sample complex option.

TABLE 6 | Correlations in the CCFA MTMM model of the latent factors and internal consistencies.

\begin{tabular}{|c|c|c|c|c|c|c|c|c|}
\hline \multirow[b]{2}{*}{ Report } & \multicolumn{2}{|c|}{ Student report } & \multicolumn{2}{|c|}{ Teacher report } & \multicolumn{2}{|c|}{ Mother report } & \multicolumn{2}{|c|}{ Father report } \\
\hline & Bullying & Victim & Bullying & Victim & Bullying & Victim & Bullying & Victim \\
\hline \multicolumn{9}{|l|}{ Student } \\
\hline Bullying & $(0.84)$ & & & & & & & \\
\hline Victim & $0.72^{\star \star \star *}$ & $(0.80)$ & & & & & & \\
\hline \multicolumn{9}{|l|}{ Teacher } \\
\hline Bullying & $0.33^{* * *}$ & $0.25^{\star \star \star}$ & $(0.94)$ & & & & & \\
\hline Victim & $0.22^{* *}$ & $0.27^{\star \star \star}$ & $0.88^{\star \star \star *}$ & $(0.86)$ & & & & \\
\hline \multicolumn{9}{|l|}{ Mother } \\
\hline Bullying & $0.33^{* \star * *}$ & $0.26^{\star \star \star}$ & $0.53^{\star \star \star}$ & $0.35^{\star \star \star}$ & $(0.87)$ & & & \\
\hline Victim & $0.20^{* *}$ & $0.35^{\star \star \star}$ & $0.40^{\star \star \star}$ & $0.45^{\star \star \star}$ & $0.74^{* \star *}$ & (0.90) & & \\
\hline \multicolumn{9}{|l|}{ Father } \\
\hline Bullying & $0.43^{* * *}$ & $0.26^{\star \star}$ & $0.51^{\star \star \star}$ & $0.39^{* \star \star}$ & $0.92^{\star \star \star}$ & $0.50^{\star \star \star}$ & (0.89) & \\
\hline Victim & $0.26^{\star \star}$ & $0.36^{\star \star \star}$ & $0.33^{\star \star \star}$ & $0.29^{\star \star \star}$ & $0.50^{\star \star \star}$ & $0.72^{\star \star \star}$ & $0.79^{\star \star \star *}$ & (0.91) \\
\hline
\end{tabular}

Note. Main diagonal (values in parentheses): reliabilities (McDonald $\omega$ ). Monotrait-heteromethod correlations are marked in grey. ${ }^{*} \mathrm{p}<0.05 .{ }^{* *} \mathrm{p}<0.01{ }^{* * *} \mathrm{p}<0.001$.

heteromethod correlations) were also all significant but varied considerably. In general, the agreement between student reports and adult reports (i.e., teacher, mother, and father) was low to moderate. The lowest agreement was observed between student reports and teacher reports for victimization (0.27). For bullying, the agreement was only slightly higher (0.33). The agreement between student reports and parent reports was somewhat higher. Contrary to expectations, the agreement for victimization was not or only marginally higher than for bullying. Further, the agreement between student reports and adult reports tended to be lower than between teacher and parent reports. The agreement between mothers and fathers was notably high (bullying: 0.92; victimization: 0.72).

\section{DISCUSSION}

The present study examined the agreement of bullying reports from the perspectives of students, peers, parents, and teachers using different methods (i.e., a short questionnaire and sociometric nominations).

\section{Sociometric Nominations}

Results from peer and teacher nominations regarding physical and relational bullying supported the assumption that teachers are more likely to recognize physical rather than relational bullying. As noted by Mazzone et al., 2012, the tendency of teachers to underestimate certain types of bullying (e.g., relational bullying) underscores the need for teacher education and teacher anti-bullying trainings to better introduce bullying and its more and less visible forms. This seems particularly important considering that teachers also tend to classify social exclusion as less severe than physical and verbal bullying, which is reflected in their intervention strategies (Yoon and Kerber, 2003).

The results further showed that there is a large fluctuation in how often students are rated by their peers to be bullying others, e.g., a range from 0 to 19 nominations per student was found for physical bullying. Pellegrini (2001) stresses the economy of peer nominations since they show the students' status within their peer group in a relatively short time. In addition to this, reliability tends to increase with data from multiple sources, meaning that a student must be nominated by various peers to be identified as a bully or victim (Branson and Cornell, 2009). Due to the large variation found in the peer nominations, the question of cutoff points for identifying bullies and victims is still prevalent and needs to be addressed in future studies.

As expected and consistent with previous research (Smith et al., 2019), significant medium-sized gender effects were found, with more frequent nominations for boys in terms of both physical and relational bullying. The gender effect between boys and girls was larger for physical bullying. Boys were more often rated for physical bullying than relational bullying, while for girls, the results were converse; thus, previous findings and our assumptions are supported (Björkqvist et al., 1992; 
Carbone-Lopez et al., 2010). Regarding the teachers' nominations, although in about one-third of the classes, teachers did not nominate individual students for bullying others, they made additional comments such as "nobody really serious" or "always different." It is therefore possible that some issues pertaining to bullying nevertheless exist in these classes. If peer nominations were reported back to teachers, they could be useful in drawing teachers' attention to bullying dynamics in their classes that teachers may not be fully aware of. However, this would require a different study design, particularly with regard to participant anonymity, and thus potentially alter the results with regard to social desirability.

The results of sociometric nominations can further be a valuable source for (peer-based) interventions at different levels (Veenstra and Huitsing, 2021). Nominations can be helpful in identifying hidden bullying issues and those students who need special support; both perpetrators and victims (Kaufman et al., 2020). Interventions can thus be targeted to individual students or groups of students rather than, or in addition to, working with the entire class. More elaborated network approaches, such as cross-sectional social network analyses, would provide even richer data on students' relationships and expand the possibilities for peer-based interventions, which are considered promising (Veenstra and Huitsing, 2021).

\section{Student, Parent, and Teacher Ratings and Their Correlation}

In our study, teachers generally reported the highest levels of bullying, followed by students, fathers, and mothers. Students reported significantly higher levels of being a victim compared to the other raters. However, the ratings of mothers, fathers, and teachers did not differ significantly. Overall, the results neither reject nor significantly support our assumption that teachers are more likely to recognize bullying than victimization, and the reversed relation for parents.

In connection with relational adjustment, Ladd and Kochenderfer-Ladd (2002) found no single-informant measure to be the best predictor; however, the multiinformant composite measure of self, peer, teachers, and parents reports yielded better estimates than any of the single-informant measures. As Ladd and KochenderferLadd (2002) put it, the logic behind multi-informant measures is to capture unique information from different sources due to "differences in perspectives, access to phenomena, reporting accuracy [...] and, thus, provide a set of indicators that more fully represents this construct" (p. 82). Since the differences in the perceptions of students, parents, and teachers will probably remain to some degree, it is important to collect these complementary perspectives in future studies as well. If low agreement is found between the different perspectives, this can be detrimental to bullying prevention and intervention and the aim should be to bring the perceptions closer together. Therefore, we first need to better understand the reasons behind the perception differences. In addition to the reasons given by Ladd and
Kochenderfer-Ladd (2002), contextual and cultural factors (e.g., teacher education, the media discourse on bullying, anti-bullying strategies in place, school culture or family structures) would need consideration as well as students' disclosure about bullying.

Parents and teachers often first learn about bullying and victimization by being informed about it by their children respectively students. Blomqvist et al. (2019) examined the prevalence of students telling others about bullying and victimization in a Finnish sample. Although telling someone at home (34\%) was more frequent than telling adults at school, telling teachers $(20,6 \%)$ was more common in this sample than in earlier studies (3-18\%). The authors discuss sample characteristics and school culture as possible explanations for their findings. They suggest that Finnish students may "perceive adults at school as more reliable and approachable than students in other countries do" (p. 6). Further research is needed to prove this. However, students must be encouraged to share their experiences and perceptions with relevant adults in their surroundings. Perhaps elements of school culture and teacherstudent relationships in Finnish schools can serve as good examples here. An improved understanding of perception differences should subsequently be used to inform intervention development.

It seems important to understand who recognizes bullying and to what extent in order to better coordinate policy and practice. From a socio-ecological perspective, bullying is influenced reciprocally not only by multiple participants such as peers in the classroom but also - as mentioned above - by multiple factors, including family, school, and community (Espelage and Swearer, 2010). There is agreement about the responsibility and impact of parents and teachers, for example, where it concerns the prevention of bullying or effective interventions. Wholeschool programs against bullying need to be sustained and intensive to be effective, but they are especially successful if parents are involved and the programs are implemented with fidelity, which is often the responsibility of teachers (Ttofi and Farrington, 2011; Menesini and Salmivalli, 2017). Larger numbers of bullying and victimization reports from teachers and parents than from students may indicate an increased sensitivity to bullying of this groups and can therefore be considered as positive for the implementation of successful interventions or prevention strategies.

In this study, teachers reported the highest levels of bullying, which may indicate their sensitivity to bullying behavior in their classes. Nevertheless, this result was surprising considering some contextual factors in Austria. On the one hand in most of the Austrian teacher education curricula a systematic education on bullying and its prevention is still lacking (Burger et al., 2015). On the other hand, there are no specific guidelines, policies or prevention programs on bullying that would be the same for all school types or even within a federal state. The ViSC program for example, which is the most prominent measures against violence in Austrian schools, was promoted between 2008 and 2013 in Austrian secondary schools (Yanagida et al., 2019). As the teachers in our sample were teaching in 4 th grade classes of primary schools, and the data collection dates to 2016, it can be 
assumed that the ViSC program has a marginal impact, if any, on teachers' perception in the current study. The reasons for their increased perception therefore remain the subject of further investigation. However, in light of bullying prevention, teachers' increased attention to bullying can generally be considered an advantage.

The significantly higher levels of victimization reported by students are in line with previous research (Demaray et al., 2013) and indicate that adults underestimate the levels of victimization experienced by students. Ladd and Kochenderfer-Ladd (2002) suggest that subjective bias such as the exaggeration of severity or frequency may inflate the students' reports, or that the reports may be accurate but indicate higher levels of victimization because more instances are recalled.

Taking a closer look at the results of the MTMM analyses on the agreements between ratings, we expected to find higher agreement between student and parent reports than between student and teacher reports. The data generally supports this assumption but with only slightly higher agreement between students and parents. The agreement for victimization was not higher or only marginally higher than that for bullying, which is not in line with our expectations. However, the findings indicate a tendency toward a lower agreement between student and adult reports than among adult reports (teachers, mothers, and fathers). Compared to existing studies, it seems to be unique to our study that the sample includes reports from both parents (mothers and fathers) along with the other three groups of respondents. The notably high agreement between the ratings of mothers and fathers for both bullying and victimization corroborates the research strategy of previous (and potentially future) studies to include only one parent.

\section{Limitations and Future Research}

There are several limitations of this study. First, although bullying is assessed from various perspectives, it is inadequate to deduce bullying prevalence estimates from these sources for Austria. As Solberg and Olweus (2003) stated, prevalence estimates can hardly be drawn from peer ratings, and this also applies to teacher ratings. One major problem is that a cutoff point must be determined in order to identify those students, e.g., one standard deviation above the mean, who can be classified as bullies or victims, or a decision has to be made about which proportion or what number of peers a student must have been nominated by to be classified as a victim or bully. Even if the decisions for differentiating criteria or cutoff points themselves stay, at least to some extent, arbitrary it is important to ensure replicability. Therefore, the rationale for the researchers' decisions needs to be revealed and argued as well as operational definitions of the constructs central to the study.

Second, due to the topic and objective of the study, the sampling strategy was purposive, and therefore the sample is not representative. Since the main topic of the ATIS-STEP survey was "inclusive schooling", we can presume that only those school principals and teachers who were highly motivated to deal with this topic took part in the study. This might result in an extremegroup-sampling because those with especially positive or negative experiences regarding inclusive schooling might be more interested in studies like this (Schwab, 2018). However, this may also be an advantage for the analysis of bullyingassociated variables, as this topic was not known to the participants, or they were not primarily interested in it.

Third, in this study the operational definition of bullying - a subcategory of aggressive behavior characterized by the intention of the perpetrator(s), repetition of violating activities, and an imbalance of power (Olweus, 1993; 1996a) — was not shared with the participants. As a result, participants may have imagined different things about bullying. This approach also differs from some of the earlier studies comparing agreements of perceptions that offered bullying definitions (e.g., Cornell and Brockenbrough, 2004; Demaray et al., 2013) and therefore hampers comparability with these studies.

Fourth, while the CFA-MTMM analyses are appropriate to investigate for agreement between different perspectives, the correlations between other reports (e.g., mother and father ratings) may also reflect shared bias instead of convergent validity. To address this limitation, future studies could apply a correlated trait-correlated method minus one model (e.g., Eid et al., 2008) to examine convergent validity of student self-reports with other reports.

Fifth, the results of the current study do not provide information on the bullying situation in single classrooms. Atria et al. (2007) interpret the variability of bullying from 0 to $54.5 \%$ between classes as a very important aspect of bullying, which is not found in the current research on bullying, where prevalence rates are calculated for the whole sample under study. They also suggest further systematic investigation into which factors at a school-class level may explain these differences. A multi-informant assessment could be of great value for this purpose. The goal of a subsequent study could be to analyze the existing data at the level of single classrooms. Further, it would be interesting to investigate whether teachers and parents who claim a good relationship with their students and children, respectively, are more likely to have correlating perceptions with the students' self-reports on bullying. Another objective, which could be explored with a detailed analysis of the existing data, is to investigate whether friendships work as protection from bullying in the context of the school class. This would also include an analysis of the data on a single-student level.

\section{DATA AVAILABILITY STATEMENT}

The datasets presented in this article are not readily available. Due to the nature of this research, participants of this study did not agree for their data to be shared publicly, so supporting data is not available. Requests to access the datasets should be directed to SS, susanne.schwab@univie.ac.at.

\section{ETHICS STATEMENT}

Ethical review and approval was not required for the study on human participants in accordance with the local legislation and institutional requirements. Written informed consent to 
participate in this study was provided by the participants or the participants' legal guardian/next of kin.

\section{AUTHOR CONTRIBUTIONS}

AP, SS and CZ, contributed to conception and design of the study. SS provided the database. $\mathrm{CZ}$ and SS performed the statistical analysis. AP wrote the first draft of the manuscript. CZ and SS wrote sections of the manuscript, especially the results. All authors contributed to manuscript revision, reviewed, and approved the submitted version.

\section{REFERENCES}

Atria, M., Strohmeier, D., and Spiel, C. (2007). The Relevance of the School Class as Social Unit for the Prevalence of Bullying and Victimization. Eur. J. Dev. Psychol. 4 (4), 372-387. doi:10.1080/17405620701554560

Bauman, S., and Del Rio, A. (2006). Preservice Teachers' Responses to Bullying Scenarios: Comparing Physical, Verbal, and Relational Bullying. J. Educ. Psychol. 98 (1), 219-231. doi:10.1037/0022-0663.98.1.219

Bell, K. J. S., and Willis, W. G. (2016). Teachers' Perceptions of Bullying Among Youth. J. Educ. Res. 109 (2), 159-168. doi:10.1080/00220671.2014.931833

Bilz, L., Schubarth, W., Dudziak, I., Fischer, S., Niproschke, S., Ulbricht, J., et al. (2017). Gewalt und Mobbing an Schulen. Wie sich Gewalt und Mobbing entwickelt haben, wie Lehrerintervenieren und welche Kompetenzen sie brauchen. Bad Heilbrunn: Klinkhardt.

Björkqvist, K., Lagerspetz, K., and Kaukiainen, A. (1992). Do girls Manipulate and Boys Fight? Developmental Trends in Regard to Direct and Indirect Aggression. Aggress. Behav. 18, 117-127. doi:10.1002/1098-2337(1992)18:2<117:AIDAB2480180205>3.0.CO;2-3

Blomqvist, K., Saarento-Zaprudin, S., and Salmivalli, C. (2019). Telling Adults about One's Plight as a Victim of Bullying: Student- and Context-Related Factors Predicting Disclosure. Scand. J. Psychol. 61 (1), 151-159. doi:10.1111/ sjop. 12521

Boulton, M. J. (1997). Teachers' Views on Bullying: Definitions, Attitudes and Ability to Cope. Br. J. Educ. Psychol. 67 ( Pt 2), 223-233. doi:10.1111/j.20448279.1997.tb01239.x

Branson, C. E., and Cornell, D. G. (2009). A Comparison of Self and Peer Reports in the Assessment of Middle School Bullying. J. Appl. Sch. Psychol. 25 (1), 5-27. doi:10.1080/15377900802484133

Browne, M. W., and Cudeck, R. (1993). "Alternative Ways of Assessing Model Fit," in Testing Structural Equation Models. Editors K. A. Bollen and J. S. Long (Newbury Park, CA: Sage Publications, Inc.), 136-162.

Burger, C., Strohmeier, D., Spröber, N., Bauman, S., and Rigby, K. (2015). How Teachers Respond to School Bullying: An Examination of Self-Reported Intervention Strategy Use, Moderator Effects, and Concurrent Use of Multiple Strategies. Teach. Teach. Edu. 51, 191-202. doi:10.1016/ j.tate.2015.07.004

Carbone-Lopez, K., Esbensen, F.-A., and Brick, B. T. (2010). Correlates and Consequences of Peer Victimization: Gender Differences in Direct and Indirect Forms of Bullying. Youth Violence and Juvenile Justice 8 (4), 332-350. doi:10.1177/1541204010362954

Casper, D. M. (2021). "Types of Traditional (Offline) Bullying," in The Wiley Blackwell Handbook of Bullying. Editors P. Smith and J. O'Higgins Norman (Wiley-Blackwell), 1, 96-119.

C. Currie, S. Nic Gabhainn, E. Godeau, C. Roberts, R. Smith, D. Currie, et al. (Editors) (2008). “Inequalities In Young People's Health: HBSC International Report From the 2005/06 Survey. Health Policy For Children And Adolescents, 5. WHO Regional Office for Europe,". Available at: http://www.euro.who. int/_data/assets/pdf_file/0005/53852/E91416.pdf?ua=1 (Accessed 05 12, 2020).

Chen, L.-M., Wang, L.-C., and Sung, Y.-H. (2018). Teachers' Recognition of School Bullying According to Background Variables and Type of Bullying. J. Educ. Cult. Psychol. Stud. 18, 147-163. doi:10.7358/ecps-2018-018-chen

\section{FUNDING}

This work was supported by the Styrian Government (Grant Number: ABT08-247083/2015-34). Open access funding was provided by the University of Vienna.

\section{ACKNOWLEDGMENTS}

We thank Mike Lehofer for his support with the data collection and data entry.

Christensen, L. L., Fraynt, R. J., Neece, C. L., and Baker, B. L. (2012). Bullying Adolescents with Intellectual Disability. J. Ment. Health Res. Intellect. Disabilities 5 (1), 49-65. doi:10.1080/19315864.2011.637660

Cole, J., Cornell, D., and Sheras, P. (2006). Identification of School Bullies by Survey Methods. Prof. Sch. Couns. 9, 305-313. doi:10.1177/ 2156759X0500900417doi:10.5330/prsc.9.4.wh4n8n4051215334

Cornell, D. G., and Bandyopadhyay, S. (2010). "The Assessment of Bullying," in Handbook of Bullying in Schools. An International Perspective. Editors S. R. Jimerson, S. M. Swearer, and D. L. Espelage (New York: Routledge), 265-276.

Cornell, D. G., and Brockenbrough, K. (2004). Identification of Bullies and Victims. J. Sch. Violence 3 (2-3), 63-87. doi:10.1300/J202v03n02_05

Cornell, D. G., Sheras, P. L., and Cole, J. C. M. (2006). “Assessment of Bullying,” in Handbook of School Violence and School Safety: From Research to Practice. Editors S. R. Jimerson and M. Furlong (Lawrence Erlbaum Associates Publishers), 191-209.

Craig, W. M., and Harel, Y. (2004). "Bullying, Physical Fighting and Victimization," in Young People's Health in Context. Health Behaviour in School-Aged Children (HBSC) Study: International Report from the 2001/ 2002 Survey. Editors C. Currie, C. Roberts, A. Morgan, R. Smith, W. Settertobulte, O. Samdal, et al. (Copenhagen: Health Policy for Children and Adolescents), 4, 133-144. WHO Regional Office for Europe. http://www. euro.who.int/_data/assets/pdf_file/0008/110231/e82923.pdf?ua=1 $05 \quad 12$, 2020)., No.

De Laet, S., Colpin, H., Vervoort, E., Doumen, S., Van Leeuwen, K., Goossens, L., et al. (2015). Developmental Trajectories of Children's Behavioral Engagement in Late Elementary School: Both Teachers and Peers Matter. Dev. Psychol. 51 (9), 1292-1306. doi:10.1037/a0039478

Demaray, M. K., Malecki, C. K., Secord, S. M., and Lyell, K. M. (2013). Agreement Among Students', Teachers', and Parents' Perceptions of Victimization by Bullying. Child. Youth Serv. Rev. 35 (12), 2091-2100. doi:10.1016/ j.childyouth.2013.10.018

Eid, M., Nussbeck, F. W., Geiser, C., Cole, D. A., Gollwitzer, M., and Lischetzke, T. (2008). Structural Equation Modeling of Multitrait-Multimethod Data: Different Models for Different Types of Methods. Psychol. Methods 13 (3), 230-253. doi:10.1037/a0013219

Espelage, E., and Swearer, S. (2010). “A Social-Ecological Model for Bullying Prevention and Intervention: Understanding the Impact of Adults in the Social Ecology of Youngsters," in Handbook of Bullying in Schools: An International Perspective. Editors S. R. Jimerson, S. M. Swearer, and D. L. Espelage (Taylor \& Francis), 347-362.

Fekkes, M., Pijpers, F. I., and Verloove-Vanhorick, S. P. (2005). Bullying: Who Does what, when and where? Involvement of Children, Teachers and Parents in Bullying Behavior. Health Educ. Res. 20 (1), 81-91. doi:10.1093/her/cyg100

Felder-Puig, R., Teutsch, F., Ramelow, D., and Maier, G. (2019).Gesundheit und Gesundheitsverhalten von österreichischen Schülerinnen und Schülern. Ergebnisse des WHO-HBSC-Survey 2018. Available at: https:/www. sozialministerium.at/cms/site/attachments/8/8/2/CH4154/CMS1562043067885/ 2018_hbsc-bericht_mit_alternativtexten_final.pdf [Accessed 12.05.2020].

Gradinger, P., Yanagida, T., Strohmeier, D., and Spiel, C. (2016). Effectiveness and Sustainability of the ViSC Social Competence Program to Prevent Cyberbullying and Cyber-Victimization: Class and Individual Level Moderators. Aggress Behav. 42 (2), 181-193. doi:10.1002/ab.21631 
Gradinger, P., Strohmeier, D., and Spiel, C. (2012). "Motives for Bullying Others in Cyberspace," in Cyberbullying in the Global Playground: Research from International Perspectives, 263-284. doi:10.1002/9781119954484.ch13

Gradinger, P., Strohmeier, D., and Spiel, C. (2017). Parents' and Teachers' Opinions on Bullying and Cyberbullying Prevention. Z. für Psychol. 225 (1), 76-84. doi:10.1027/2151-2604/a000278

Graf, D., Yanagida, T., and Spiel, C. (2019a). Sensation Seeking's Differential Role in Face-To-Face and Cyberbullying: Taking Perceived Contextual Properties into Account. Front. Psychol. 10, 1572. doi:10.3389/fpsyg.2019.01572

Graf, D., Yanagida, T., and Spiel, C. (2019b). Through the Magnifying Glass: Empathy's Differential Role in Preventing and Promoting Traditional and Cyberbullying. Comput. Hum. Behav. 96, 186-195. doi:10.1016/ j.chb.2019.02.007

Holt, M. K., Kaufman Kantor, G., and Finkelhor, D. (2008). Parent/Child Concordance about Bullying Involvement and Family Characteristics Related to Bullying and Peer Victimization. J. Sch. Violence 8 (1), 42-63. doi:10.1080/15388220802067813

Houndoumadi, A., and Pateraki, L. (2001). Bullying and Bullies in Greek Elementary Schools: Pupils' Attitudes and Teachers'/parents' Awareness. Educ. Rev. 53 (1), 19-26. doi:10.1080/00131910120033619

Hu, L. t., and Bentler, P. M. (1999). Cutoff Criteria for Fit Indexes in Covariance Structure Analysis: Conventional Criteria versus New Alternatives. Struct. Equation Model. A Multidisciplinary J. 6 (1), 1-55. doi:10.1080/ 10705519909540118

Hymel, S., and Swearer, S. M. (2015). Four Decades of Research on School Bullying: An Introduction. Am. Psychol. 70 (4), 293-299. doi:10.1037/a0038928

Inchley, J., Currie, D., Budisavljevic, S., Torsheim, T., Jåstad, A., Cosma, A., et al. (2020). Spotlight on Adolescent Health and Well-Being. Findings from the 2017/ 2018 Health Behaviour in School-Aged Children (HBSC) Survey in Europe and Canada. International Report. Key findings, 1. Copenhagen: WHO Regional Office for Europe. Available at: https://apps.who.int/iris/bitstream/handle/ 10665/332091/9789289055000-eng.pdf(08 17, 2021).

Juvonen, J., Nishina, A., and Graham, S. (2001). "Self-views versus Peer Perceptions of Victim Status Among Early Adolescents," in Peer Harassment in School: The Plight of the Vulnerable and Victimized. Editors J. Juvonen and S. Graham (New York: The Guilford Press), 105-124.

Kaufman, T. M. L., Huitsing, G., Bloemberg, R., and Veenstra, R. (2020). The Systematic Application of Network Diagnostics to Monitor and Tackle Bullying and Victimization in Schools. Int. J. Bullying Prev. 3, 75-87. doi:10.1007/ s42380-020-00064-5

Ladd, G. W., and Kochenderfer-Ladd, B. (2002). Identifying Victims of Peer Aggression from Early to Middle Childhood: Analysis of Cross-Informant Data for Concordance, Estimation of Relational Adjustment, Prevalence of Victimization, and Characteristics of Identified Victims. Psychol. Assess. 14 (1), 74-96. doi:10.1037/1040-3590.14.1.7410.1037//1040-3590.14.1.74

Lee, T., and Cornell, D. (2009). Concurrent Validity of the Olweus Bully/Victim Questionnaire. J. Sch. Violence 9 (1), 56-73. doi:10.1080/15388220903185613

Marsh, H. W., Hau, K.-T., and Wen, Z. (2004). In Search of golden Rules: Comment on Hypothesis-Testing Approaches to Setting Cutoff Values for Fit Indexes and Dangers in Overgeneralizing Hu and Bentler's (1999) Findings. Struct. Equation Model. A Multidisciplinary J. 11 (3), 320-341. doi:10.1207/ s15328007sem1103_2

Mazzone, A., Kollerová, L., and O’Higgins Norman, J. (2012). “Teachers' Attitudes toward Bullying: what Do We Know and where Do We Go from Here?," in The Wiley Blackwell Handbook of Bullying. Editors P. Smith and J. O'Higgins Norman (Wiley-Blackwell), 1, 139-157.

Menesini, E., and Salmivalli, C. (2017). Bullying in Schools: the State of Knowledge and Effective Interventions. Psychol. Health Med. 22 (Suppl. 1), 240-253. doi:10.1080/13548506.2017.1279740

Molcho, M., Craig, W., Due, P., Pickett, W., Harel-Fisch, Y., and Overpeck, M. (2009). Cross-national Time Trends in Bullying Behaviour 1994-2006: Findings from Europe and North America. Int. J. Public Health 54 Suppl 2 (Suppl. 2), 225-234. HBSC Bullying Writing Group. doi:10.1007/s00038-009-5414-8

Molcho, M. (2012). "Being Bullied and Bullying Others," in Social Determinants of Health and Well-Being Among Young People. Health Behaviour in School-Aged Children (HBSC) Study: International Report from the 2009/2010 Survey. Editor C. Currie (Health Policy for Children and Adolescents), No. 6, 191-201. WHO Regional Office for Europe.
http://www.euro.who.int/_data/assets/pdf_file/0003/163857/Socialdeterminants-of-health-and-well-being-among-young-people.pdf?ua=1 05 12, 2020).

Muthén, L. K., and Muthén, B. (1998-2017). Mplus User's Guide. Eigthth edition. Los Angeles, CA: Muthén \& Muthén.

Newgent, R. A., Lounsbery, K. l. L., Keller, E. A., Baker, C. R., Cavell, T. A., and Boughfman, E. M. (2009). Differential Perceptions of Bullying in the Schools: A Comparison of Student, Parent, Teacher, School Counselor, and Principal Reports. J. Sch. Couns. 7 (38), 1-33.

Nussbeck, F. W., Eid, M., and Lischetzke, T. (2006), Analysing MultitraitMultimethod Data with Structural Equation Models for Ordinal Variables Applying the WLSMV Estimator: What Sample Size Is Needed for Valid Results? Br. J. Math. Stat. Psychol. 59 (1), 195-213. doi:10.1348/ $000711005 \times 67490$

OECD (2017). PISA 2015 Results (Volume III): Students' Well-Being. Paris: PISA, OECD Publishing. doi:10.1787/9789264273856-en

OECD (2019). PISA 2018 Results (Volume I): What Students Know and Can Do. Paris: PISA, OECD Publishing. doi:10.1787/5f07c754-en

Olweus, D. (1978). Aggression in Schools: Bullies and Whipping Boys. Hemisphere Press (Wiley.

Olweus, D. (1996a). Bullying at School: Knowledge Base and an Effective Intervention Program. Ann. NY Acad. Sci. 794, 265-276. doi:10.1111/j.17496632.1996.tb32527.x

Olweus, D. (1993). Bullying at School: What We Know and what We Can Do. Blackwell.

Olweus, D. (1973). Hackkycklingar Och Översittare. Forskning Om Skolmobbning. Stockholm: Almqvist \& Wicksell.

Olweus, D. (1996b). The Revised Olweus Bully/Victim Questionnaire. Bergen: Mimeo, Research Center for Health Promotion.

Pellegrini, A. D., and Bartini, M. (2000). An Empirical Comparison of Methods of Sampling Aggression and Victimization in School Settings. J. Educ. Psychol. 92 (2), 360-366. doi:10.1037/0022-0663.92.2.360

Pellegrini, A. D. (2001). "Sampling Instances of Victimization in Mile School: A Methodological Comparison," in Peer Harassment in School: The Plight of the Vulnerable and Victimized. Editors J. Juvonen and S. Graham (New York, NY: Guilford Press), 125-144.

Salmivalli, C., Lagerspetz, K., Björkqvist, K., Österman, K., and Kaukiainen, A. (1996). Bullying as a Group Process: Participant Roles and Their Relations to Social Status within the Group. Aggress. Behav. 22 (1), 1-15. doi:10.1002/(sici) 1098-2337(1996)22:2<99:aid-ab3>3.0.co;2-p

Schwab, S. (2018). Attitudes Towards Inclusive Schooling. A study on Students', Teachers' and Parents' attitudes. (Beiträge der Bildungsforschung; Band 4). Münster: Waxmann Verlag.

Smith, P. K., López-Castro, L., Robinson, S., and Görzig, A. (2019). Consistency of Gender Differences in Bullying in Cross-Cultural Surveys. Aggression Violent Behav. 45, 33-40. doi:10.1016/j.avb.2018.04.006

Smith, P. K. (2014). Understanding School Bullying: Its Nature \& Prevention Strategies. London: Sage. doi:10.4135/9781473906853

Solberg, M. E., and Olweus, D. (2003). Prevalence Estimation of School Bullying with the Olweus Bully/Victim Questionnaire. Aggr. Behav. 29 (3), 239-268. doi:10.1002/ab.10047

Spiel, C., and Strohmeier, D. (2011). National Strategy for Violence Prevention in the Austrian Public School System: Development and Implementation. Int. J. Behav. Dev. 35 (5), 412-418. doi:10.1177/0165025411407458

Stockdale, M. S., Hangaduambo, S., Duys, D., Larson, K., and Sarvela, P. D. (2002). Rural Elementary Students', Parents', and Teachers' Perceptions of Bullying. Am. J. Health Behav. 26 (4), 266-277. doi:10.5993/AJHB.26.4.3

Strohmeier, D., and Gradinger, P. (2021). Teachers' Knowledge and Intervention Strategies to Handle Hate-Postings. Eur. J. Dev. Psychol., 1-15. doi:10.1080/ 17405629.2021.1877130

Strohmeier, D., Solomontos-Kountouri, O., Burger, C., and Doğan, A. (2021). Cross-National Evaluation of the ViSC Social Competence Programme: Effects on Teachers. Eur. J. Dev. Psychol., 1-17. in press. doi:10.1080/ 17405629.2021.1880386

Strohmeier, D., and Spiel, C. (2003). Immigrant Children in Austria. J. Appl. Sch. Psychol. 19 (2), 99-116. doi:10.1300/J008v19n02_07

Strohmeier, D., and Wagner, P. (2019). Mobbing und Migration in oberösterreichischen Schulen. jst 6 (2), 128-135. doi:10.33196/jst201902012801 
Sturaro, C., van Lier, P. A., Cuijpers, P., and Koot, H. M. (2011). The Role of Peer Relationships in the Development of Early School-Age Externalizing Problems. Child. Dev. 82, 758-765. doi:10.1111/j.1467-8624.2010.01532.x

Ttofi, M. M., and Farrington, D. P. (2011). Effectiveness of School-Based Programs to Reduce Bullying: A Systematic and Meta-Analytic Review. J. Exp. Criminol 7 (1), 27-56. doi:10.1007/s11292-010-9109-1

Vaillancourt, T., Brittain, H., Bennett, L., Arnocky, S., McDougall, P., Hymel, S., et al. (2010). Places to Avoid: Population-Based Study of Student Reports of Unsafe and High Bullying Areas at School. Can. J. Sch. Psychol. 25 (1), 40-54. doi:10.1177/0829573509358686

Veenstra, R., and Huitsing, G. (2021). "Social Network Approaches to Bullying and Victimization," in The Wiley Blackwell Handbook of Bullying. Editors P. Smith and J. O'Higgins Norman (Wiley-Blackwell), Vol. 1, 196-214.

Wachs, S., Bilz, L., Niproschke, S., and Schubarth, W. (2019). Bullying Intervention in Schools: A Multilevel Analysis of Teachers' Success in Handling Bullying from the Students' Perspective. The J. Early Adolescence 39 (5), 642-668. doi: $10.1177 / 0272431618780423$

Walsh, S., and Cosma, A. (2016). "Bullying: Being Bullied and Bullying Others," in Growing up Unequal: Gender and Socioeconomic Differences in Young Peoples Health and Well-Being. Health Behaviour in School-Aged Children (HBSC) Study: International Report from the 2013/2014 Survey. Editor J. Inchley (Copenhagen: Health Policy for Children and Adolescents), 7, 197-211. Kopenhagen: WHO Regional Office for Europe. http://www.euro.who.int/ data/assets/pdf_file/0003/303438/HSBC-No.7-Growing-up-unequal-FullReport.pdf?ua=1 05 12, 2020).

Wang, J., and Wang, X. (2012). Structural Equation Modeling. Applications Using Mplus. Wiley.
Yanagida, T., Strohmeier, D., and Spiel, C. (2019). Dynamic Change of Aggressive Behavior and Victimization Among Adolescents: Effectiveness of the ViSC Program. J. Clin. Child. Adolesc. Psychol. 48 (00), S90-S15. doi:10.1080/ 15374416.2016.1233498

Yoon, J., and Bauman, S. (2014). Teachers: A Critical but Overlooked Component of Bullying Prevention and Intervention. Theor. Into Pract. 53 (4), 308-314. doi:10.1080/00405841.2014.9472210.1080/00405841.2014.947226

Yoon, J. S., and Kerber, K. (2003). Bullying. Res. Edu. 69 (1), 27-35. doi:10.7227/ RIE.69.3

Conflict of Interest: The authors declare that the research was conducted in the absence of any commercial or financial relationships that could be construed as a potential conflict of interest.

Publisher's Note: All claims expressed in this article are solely those of the authors and do not necessarily represent those of their affiliated organizations, or those of the publisher, the editors and the reviewers. Any product that may be evaluated in this article, or claim that may be made by its manufacturer, is not guaranteed or endorsed by the publisher.

Copyright (C) 2021 Paljakka, Schwab and Zurbriggen. This is an open-access article distributed under the terms of the Creative Commons Attribution License (CC BY). The use, distribution or reproduction in other forums is permitted, provided the original author(s) and the copyright owner(s) are credited and that the original publication in this journal is cited, in accordance with accepted academic practice. No use, distribution or reproduction is permitted which does not comply with these terms. 